\title{
FAC Regimen
}

National Cancer Institute

\section{Source}

National Cancer Institute. FAC Regimen. NCI Thesaurus. Code C138099.

A chemotherapy regimen consisting of fluorouracil, doxorubicin and intravenous

cyclophosphamide, used as a treatment for recurrent and metastatic breast cancer. 